\title{
Research on Training Mode of Automobile Service Weiguang $\mathrm{Ye}^{1, \mathrm{a}}$ \\ ${ }^{1}$ College of applied technology, Jilin University, Changchun Jilin, China an4n4china@126.com
}

Keywords: Automobile, Service, Training, Reform.

\begin{abstract}
In recent years, the car service professionals are very scarce in the automotive market after, but the quality of personnel is generally poor. It is difficult to that will undoubtedly hinder our national auto service industry healthy development. This paper analyzes the training mode of the automobile service and finds that it can not meet and adapt to the requirements of the personnel training in the automobile service industry. It shows that the existing problems and shortcomings of the automobile service put forward the car service professional training program to meet the social and business needs. It is suggesut that curriculum system the teaching staff and the ability to practice three aspects should be refom on the automotive service training model to reform.
\end{abstract}

\section{汽车服务专业培养模式研究 \\ 叶玮光 ${ }^{1, a}$ \\ 1吉林大学应用技术学院, 长春, 吉林, 中国 an4n4china@126.com}

关键词: 汽车; 服务; 培养; 改革

中文摘要. 目前在汽车后市场所从事汽车服务专业人才十分紧缺, 人员素质普遍偏低, 难以 满足广大消费者对汽车服务领域日益提高的消费需求, 这无疑会阻碍我们国家汽车服务行业 的健康发展。本文通过分析汽车服务专业的培养模式, 发现其不能满足并适应汽车服务行业 对人材培养的要求, 表明其目前存在的问题和不足, 提出了适应社会和企业需求的汽车服务 专业培养方案, 着重从课程体系改革、师资队伍建设、锻炼实践能力三个方面提出对汽车服 务专业培养模式进行改革。

\section{1. 引言}

随着我国经济的发展, 汽车保有数量呈现逐年增加的良好发展趋势。因此对于汽车后市 场的服务业也蕴藏着非常巨大的商机及相关人才的需求。目前在汽车后市场所从事汽车服务 专业人才十分紧缺, 人员素质普遍偏低, 难以满足广大消费者对汽车服务领域日益提高的消 费需求, 这无疑会阻碍我们国家汽车服务行业的健康发展。应用技术型院校如何在此背景下 培养出复合型高素质汽车服务技术人才是我们面临的紧迫问题。

\section{2. 汽车服务行业人员现状}

我国汽车行业从业人员整体文化水平不高、缺少专业知识、没有较强的服务意识。在汽 车研发、服务以及文化等方面还无法满足当前汽车服务行业的需求, 无法符合经济全球化发 展的要求。具体表现如下: 
汽车销售人员对不同消费者的需求理解不够透彻, 目标客户不明确, 远远没有做到像丰 田公司那样从汽车驾驶学校到每个家庭的完整的市场覆盖, 尚须向以需求管理为核心的整合 营销发展。汽车服务人员仍处于简单的产品维修阶段, 等到车辆出现问题了, 客户才到维修 站进行修理, 远远没有达到主动为客户服务的维护保养阶段, 而且服务质量还有待进一步提 升。汽车文化企业宣传人员没有抓住消费者需求, 真正让消费者产生震撼性的影响。很多企 业没有深入分析消费者的感觉与心理需求, 推出适当的产品品牌价值塑造体系, 广告仍然停 留在统一营销形象的狂轰乱炸阶段。整个品牌塑造手段, 仍然停留在单向介绍企业产品, 而 不是针对消费者的潜在需求, 塑造品牌的价值形象。

总之, 我们国家目前非常缺少汽车服务行业的人才, 特别是不但掌握汽车技术, 而且掌 握管理技能的复合型人才。

\section{3. 汽车服务专业人材培养培养目标}

\section{1 夯实基础}

应能技术型学校需要在培育汽车相关专业的人材的时候, 必须要树立注重基础、结合实 践、就业口径宽的人才培养方向, 做到在掌握汽车基本知识的前提下做好汽车服务, 以工程 理论作为重要基础, 把汽车服务作为学科前进方向, 加强学生动手能力的培养, 培育出适应 我们国家汽车服务行业的技术应用型人才。

\section{2 一砖多能}

汽车服务业的市场需很多的既要掌握汽车基本技术又要掌握管理服务的交叉学科人才。 那么根据社会及市场需要, 在人材培养时就要注重复合型高素质人材的培养。

因此应用技术型院校培养的人材主要面向汽车维修和汽车销售等汽车服务类企业, 掌握汽 车技术分析知识和能力, 能胜任汽车维修服务顾问、汽车销售工作岗位的高素质技术技能型 人才。汽车维修服务顾问具备汽车维修接待、维修技术解答、维修业务引导、客户关系维护 的专业技能; 汽车销售岗位具备营销策划技能、汽车销售技能、汽车信贷和保险业务办理技 能、客户关系维护的专业技能; 同时兼顾培养相近工作岗位（汽车配件管理岗位、汽车保险 与理赔岗位、二手车鉴定评估与交易等岗位）的工作技能。并且通过本专业的培养，使合格 毕业生在汽车服务行业具备可持续发展的素质和能力。

\section{4. 汽车服务专业培养模式的不足}

\section{1 课程设置}

应用技术型院校的课程设置不合理。主要体现在使用的课程教材大部分是专业技术类的 课本, 讲授的理论知识比较深奥, 侧重汽车开发技术研究型人材的培养。因此容易导致讲授 的内容偏离汽车服务专业的培养目标, 影响教学效果。而汽车服务技术人材在专业方向主要 偏向基础理论知识, 讲授的知识要求理论知识表面化浅潜易懂。

\section{2 教师队伍}

由于高校教师一般属于具有深厚的理论知识, 但缺乏充足的实践经验。教师在讲授知识 的时候, 所讲的内容深奥枯燥, 不能引起学生的求知欲望, 而且所讲的内容比较陈旧, 与社 会企业的发展脱节, 影响教学效果, 不利于学生快速成长。

\section{3 教学资源}

汽车服务专业人才主要是掌握理论与实践的复合人材, 并且偏重于社会实践。但是因为 众多制约因素, 高校很难为大学生提供充足的条件用于实习, 导致培养出人材的社会适应能 
力和实际动手能力都比较弱。如何科学合理地为汽车服务专业学生创造量身定制的用于实习 的实验资源、环境场地一直是高校实践教学环节中存在的困难。

\section{5. 汽车服务专业培养模式的改革}

汽车服务专业培养模式的改革就要坚持以市场为导向, 以服务为宗旨, 以就业为目标的 办学理念; 坚持以培养具有一定交通汽车类理论知识和较强实践能力的应用型、技能型专门 人才为目标。坚持走校企合作，产学研相结合的办学道路

\section{1 课程体系改革}

学校实践课程建设。合理制定汽车服务工程专业的人才培养计划、教学目标、选择相应 的教学科目, 以达到相应的培养目标。汽车服务领域的课程主要不能按照传统的研究型大学 的课程建设的方式来安排学科理论。要求学生的理论知识深浅合适, 涉及到多领域, 比如车 辆工程、汽车电子、汽车服务与营销、汽车检测与维修技术、汽车制造与装配技术等交叉学 科。另外课程内容合理, 把知识理论说的清楚、理解透彻就足够, 将学生培养成理论知识扎 实又同时拥有较强的操作技能的人才。此外, 尽可能地结合社会和企业对人材的需求, 自编 或者合作编写应用型的精品教材。

\section{2 师资队伍建设}

专业教师必须具备扎实的专业理论功底，又要有丰富的企业实践经验。建设优质教师资 源, 还要阶段性地注重教师在新技术、新知识方面的培训。校企合作可以增强教师实践经验, 同时还可以加强学生的实践教学。通过与汽车相关企业的接触合作, 高校教师能够掌握汽车 生产服务行业的发展趋势, 以及学习和掌握最新的设计理念、技巧。建设一支实践能力强、 符合应用技术型人才培养的高水平师资队伍是培养汽车后市场人材的坚强后盾。

\section{3 锻炼实践能力}

校外生产实习是学生运用所学的理论知识在现场或生产实践中培养分析和解决问题能力 的一种实践活动。其目的是弥补学生在校内实习内容不够全面、真实的问题, 直接融入社会 企业, 开阔学生视野, 感受企业文化, 使学生对我国汽车生产、销售及维修企业的现状和发 展情况有全面的了解。

汽车服务专业，可以根据自身专业特点推行工学结合的人才培养模式，运用 “订单式”、 “顶岗实习”、“工学交替”、“教、学、做一体化” 等多种理论与实践相结合的教学模式, 全面培养学生的学习能力、实践能力和创新能力。建立并实行应用技术型院校和用人单位的 订单式培养模式, 维持长期稳定的校企合作关系, 可以充分发挥校企双方各自优势, 使实践 教学和企业生产融为一体, 促进了学生专业理论学习与职业发展能力的对接, 满足了社会和 行业的发展需求。学生通过课外实习, 不仅可使自己更好地理解和巩固专业课的理论知识, 更重要的是还可以了解本专业的具体工作内容, 提高学生的实际动手能力, 培养学生的综合 素质

\section{6. 结束语}

随着汽车服务行业的繁荣发展, 对汽车服务专业的人材需求越来越多, 人员素质的要求 不断提高。本文通过分析汽车服务专业的培养模式, 发现其不能满足并适应汽车服务行业对 人材培养的要求, 表明其目前存在的问题和不足, 提出了适应社会和企业需求的汽车服务专 业培养方案, 着重从课程体系改革、师资队伍建设、锻炼实践能力三个方面提出对汽车服务 专业培养模式进行改革。新的培养模式既注重基础理论的学习, 也需要进行工程实践环节的 教学, 使学生能够把理论知识和工程实际相结合, 成为拥有多学科交叉专业的人才, 熟练掌 
握汽车服务行业的相关技能, 使学生拥有较强的竞争力, 成为复合型高素质综合服务技能人 材。

\section{References}

[1] Xia Cheng. A Summary of China's Automobile Service Industry [J]. Vocational \& Technical Education Forum, 2008 (24): 228-229.

[2] Xinxin Lu. Investigation and Research on the Professionals of Automobile Service Engineering -Automotive Service Engineering Talent Requirements [J]. Intelligence.2013(16).

[3] Jian Zhai. Reform and Practice of the Mode of Cultivating Applied Talents Based on the Cooperation between Colleges and Enterprises [J]. Education and Teaching Forum, 2014(44).

[4] Hongfei Yin. Research on Engineering Quality Guarantee System for Application - Oriented Undergraduate Teaching [J]. Shanghai University of Engineering and Technology Teaching Research, 2007(3):21 -25.

[5] Yongfeng Shen. Probe into the Training Pattern of Technical Personnel in Automobile Service Engineering [J]. Vocational Education Research, 2008(5):79 -80.

[6] Yongbin Wang, Jie Shao, Yahua Wu. Exploration on the Construction of Practical Teaching Bases of Newly - built Local Colleges [J]. Journal of Chifeng University www.ilib.cn (Natural Science Edition ),2014,30(1). 